pigmentation was very marked and the face was dusky, the general distribution of the pigmentation being as in Case 4. On the back was a patch of erythema about eight by ten inches, sharply defined, and exhibiting dermographia on friction. When her initials were scratched upon it they stood up as wheals in bold relief. The pigmentation faded towards the hands and feet. The tongue was silvery and exfoliating. The patient had suffered from purging with tenesmus and smarting, but had passed no blood by the bowel. She attributed this to the beer she had taken, which always gave her a burning feeling in the chest and stomach. There was great tenderness on pressure over the nerves of the legs and also on the soles of the feet, with hyperæsthesia. The knee and plantar reflexes were absent ; there was no ataxia, no wasting, and no marked paresis. Examination of the chest revealed general bronchitis. The heart sounds were rather feeble, but there were no murmurs. Exertion caused dyspnoea. The pulse was 96, small, soft, and regular. Menstruation had increased, and the last period had been excessive. The thyroid gland was much enlarged, more on the right side than on the left. There was no pulsation or murmur, the increase in size having been recent. The gland had never caused her any trouble before but had become a source of much discomfort. The patient took "sixpenny" beer with her meals, three glasses per diem.

CASE 6.-A man, aged 47 years, complained that his right hand felt " asleep," with a feeling of "pins and needles." For a week his legs had become weak and numb and as if he were "standing on ice." He could not work owing to the weakness of the legs. He had had cory za for two weeks and he had also had looseness of the bowels for the same time. The skin was dry and scaly and the nipples were very brown. There was a pigmented macular eruption on both sides of the body, the buttocks, and the thighs; on the latter it was in long streaks following scratching. There was a separate patch on the right buttock two and a half inches square, and one on the abdomen. The face was dusky and expressionless. The man had difficulty in picking up pins with his right hand as he could not feel them. There was a feeling of "pins and needles" in both legs, with slight superficial anæsthesia, but great pain on pressure over the calves and the soles of his feet. The knee and plantar reflexes were absent, but the paresis was not pronounced. There was slight ataxic gait on walking with the eyes shut. There were no mental symptoms. The pulse was 86 . The heart sounds were normal. The tongue was pale and silvery. but there was no gastric disturbance. The patient confessed to taking two glasses of beer at night but no stout, and he said that he always got his beer from the same public-house.

CASE 7.-A man was admitted into the hospital complaining of loss of sensation in the arms and legs; he said that on standing or walking he felt as if a round ball were under the sole of each foot. He had been in the habit of drinking beer but not to excess, and he very seldom drank spirits. His illness commenced in October, 1900, with "cold in the head"; he had also vomiting and diarrboea. On walking he experienced pain in the calf muscles; weakness of the legs below the knees developed, and later the hands and arms became affected. He had gradually lost weight. The pigmentation of the skin was not very deep in colour with the exception of the axillæ, the groins, and the nipples. The skin was dry and desquamating in fine powdery scales; the skin of the hands and feet was shiny and bluish. The finger-nails had each a well-marked transverse ridge, indicating in period of growth the approximate date of the initial trophic disturbance. There were no special symptoms in the alimentary system. The pulse was 72 and of low tension. The heart sounds were feeble and distant but there was no bruit. There was slight general bronchitis with cough. The patient slept fairly well; there were no headache and no mental disturbance. He walked with difficulty and with a "stepping" gait. There was marked hyperæsthesia of the hands and the forearms, also of the feet and the legs. Pressure over the nerves in the calves caused great pain. The soles of the feet were very tender on pressure. There was marked wasting of the muscles of the arms and legs, with loss of contour in the limbs, loss of power, and "drop foot." The patellar reflexes were absent and the plantar reflexes were diminished. There was no cdema. The specific gravity of the urine was 1005 ; it was acid but there was no albumin or sugar.

The above series of cases exhibited a characteristic train of symptoms ; other cases, however, in which there was sufficient reason to attribute the symptoms to the same cause were less typical and varied in severity. The following may be taken as examples.

CASE 8.- A woman, after three years' abstinence from liquor, took it in excess for two weeks. Violent vomiting, diarrhœea, and depression ensued. The tongue was furred and the mouth and gums were ulcerated and painful. The pulse was 120 and was very feeble. The heart sounds were "fotal" in character. There were pains in the hands and calves, with great tenderness on pressure. The knee and plantar reflexes were exaggerated.

CASE 9. - The patient was a man who had always been in the babit of drinking from four to five pints of beer daily but who had never experienced any ill effects until the end of November, 1900, when he suffered from severe gastrointestinal symptoms and coldness and feelings of numbness in the hands and legs. When seen in the out-patients' room he was extremely depressed, with pronounced tremor, and was continually hawking up mucus from the throat. There was great pain on pressing over the nerves of the legs. The face was puffy and the skin was dry. There was no pigmentation. The patellar reflexes were exaggerated and the plantar reflexes were diminished. The pulse was 160 , very small. The heart sounds were "fœtal" in character. The face was puffy.

CASE 10.-The patient, a man, suffered from cedema of the legs with pain on pressure over the nerves. The kneereflexes were diminished. There was also anæmia. There was no pigmentation. Slight gastro-intestinal symptoms were present. The pulse was irregular, small, and frequent. The heart sounds were feeble.

CASE 11.-The patient was a man, showing pigmentation and fine desquamation round the waist, in the armpits, in the groins, and in the nipples. There were hoarseness and bronchitis but no gastro-intestinal disturbance. Pain and tenderness of the sole of the right foot were also present. The right knee reflex was absent and the left knee reflex was normal.

CASES 12 and 13.-These cases were those of two females who showed herpes zoster of the right side of the trunk with intercostal neuralgic pain. They had also pains in the hands and in the feet, with pigmentation of the trunk.

OASE 14. - This was the case of a man who had herpes zoster of the right buttock extending down the thigh to the ham.

CASE 15. - This was the case of a man who suffered severe urticaria, with pains in the arms and the legs. I he urticaria disappeared with the discontinuance of the beer. Several days later on taking beer a fresh outbreak was precipitated.

CASE 16. - The patient was a female who bad had coryza for two weeks. There were four loose motions daily. She suffered from great thirst. There were numbness in the hands and occasionally in the legs and pigmentation of the sides of the trunk. The skin was dry and desquamating particularly over a large area on the left side of the trunk. The tongue was clean, fissured, and glistening. The pulse was 80 , regular and small. There was a systolic mitral murmur.

In the majority of instances I was able to locate the establishments at which the patients had procured their beer and I felt justified in notifying without delay the names and addresses of the patients and the establishments to the medical officer of health of the city.

Liverpool.

\section{THE ROENTGEN RAYS AND THE DIAGNOSIS OF URINARY CALCULI.}

By C. MANSELL MOULLIN, M.D. OxoN., F.R.C.S. ENG., SURGEON AND LECTURER_ON SURGERY AT THE LONDON HOSPITAL.

WITHIN the last few weeks I have had under my care a series of cases which illustrate in an unusual degree the value of the Roentgen rays in the diagnosis of renal, ureteral, and vesical calculi. Thanks to the improvements in technique which have been effected in the course of the last two years the results obtained by Roentgen photographs may, so far as calculi are concerned, be regarded as final and conclusive for all ordinary cases. Unless there is some unusual difficulty, such as an abnormally stout abdomen 
or, as in one of my cases, an extreme lumbo-dorsal curvature, displacing and burying the kidney, the Roentgen rays can be relied upon to give definite and accurate information not only as to the existence of a calculus but as to its size, its exact position, and, what is even more important, whether there are other calculi present either in the same or in some other part of the urinary tract. There need, therefore, be no fear lest, as has happened before now, an operation should be performed by some mischance apon the wrong organ or on the wrong side. The best results, of course, are obtained with calculi composed of oxalate of lime, as these absorb the rays to a much greater extent than others, but even concretions of phosphate of lime can be made to throw a distinct shadow, unless they are so minute as to be of no practical importance, and a negative result can be relied upon as much as a positive one. If no calculus is shown after a second examination, repeated under varying conditions, it may be taken as certain that there is no calculus there. Out of eight cases radiographed by Lennard of Philadelphia in which the result was negative on subsequent examination nothing was found in seven cases. In the eighth case it was known at the time that the technique was faulty and that no reliance could be placed upon the result.

In many instances Roentgen photography is the only method by which the presence of a fixed calculus can be ascertained. I have published elsewhere ${ }^{1}$ a case in which I removed a small cortical calculus from the right kidney of a patient who had bad his appendix removed nine months before by another surgeon without deriving the least relief. As usual in the case of a cortical calculus there were none of the characteristic symptoms of stone in the kidney. The stone was fixed and never came into contact with the orifice of the ureter, so that there was no renal colic, or bæmaturia, or retraction of the testis, but merely constant aching pain referred to the right iliac fossa and made worse by every attempt at exertion and attended by a feeling of sickness. A single exposure revealed the canse, and with the removal of the calculus the pain ceased entirely.

Even when there is no doubt as to the existence of a calculus the assistance derived from this method of investigation is scarcely less valuable, especially in the case of renal calculi. In another patient of mine, who was under the care of Dr. J. G. Ogle of Reigate, the clinical symptoms were so definite that the diagnosis of stone in the kidney was practically certain; but nothing could be ascertained about the size of the calculus, or its position in the kidney, or whether there might not be more than one, hidden away, perhaps, in one of the calices. A single examination with the Roentgen rays proved beyond all question that there was only one stone and that it was fixed in the cortex and at the lower end of a particularly low-placed kidney. In consequence of this I was able to extract it through the smallest possible incision and with a minimum amount of manipula. tion. Had it not been for the skiagram it would have been necessary to have exposed the whole kidney, and to have palpated it thoroughly, perhaps even to have dragged it out of the wound on to the loin, first to find the stone, and then to make sure that there was no second stone present.

When the stone has left the kidney and is passing down the ureter the condition of the patient, as a rule, is such that quiet examination is not possible. In one case, however, in which the course of the stone was temporarily arrested just below the brim of the pelvis, I obtained definite information both as to its presence and its exact locality. Fortunately, under active purgation, it soon began to move on again, and it was ultimately passed without any operative measures being, required. Had it remained fixed where it was the information would have been of the utmost value in determining the exact situation for the incision. In two cases of suspected ureteral calculus under my care, in which the evidence given by the Roentgen rays was negative, the subsequent course of events proved that it was perfectly correct. In one case it was thought that there might be a calculus impacted in the lower end of the nreter, as, in addition to other symptoms, there was a peculiar prominence of the mucous membrane of the bladder just behind the orifice of the ureter and visible through the cystoscope, but on examination nothing was found. In the other case the patient, who had suffered from repeated attacks of colic down the left side of the abdomen for some months before and in whom the left kidney was unusually sensitive to pressure, died suddenly from acute intestinal strangulation a fortnight after the skiagram had been taken, and the kidney and ureter were found at the post-mortem examination to be perfectly free.

Under ordinary circumstances the Roentgen rays are not required in cases of vesical calculus. The diagnosis is easily made with a sound, aided, especially in children, by the introduction of the finger into the rectum; but there are many cases of enlargement of the prostate in which this method fails completely. Stone in the bladder is much more common in association with enlargement of the prostate than is usually believed, and is very often overlooked. Sometimes the stone lies in a definite sacculus and sometimes it is merely caught behind the prostate and held by it against the trigone. In either case, however, it never comes into contact with the neck of the bladder, it never gives rise to the characteristic symptoms, and it is exceedingly easy to miss with a sound. There may be pain, it is true, but it is not the characteristic sharp cutting pain of stone in the bladder, felt at the end of the penis, and coming on as the last few drops of urine are expelled. Micturition may be unduly frequent, but the frequency is either more marked during the night than during the day or else is so extreme that such exercise as the patient can take makes little or no difference. Blood is of ten present in the urine, but more often than not it precedes or accompanies the flow instead of following it; and though the stream of urine often stops before the bladder is emptied, it is not arrested with that abruptness and sudden pain which characterise the dropping of a calculus into the neck of the bladder and the sudden spasmodic contraction of all the muscles around it. It often happens in these cases that the only indication of the presence of $a$ calculus is the obstinate persistence of cystitis which resists all ordinary measures; and I am strongly of opinion, from the frequency with which I have found calculi present, that whenever this persistence is a prominent feature in association with enlargement of the prostate a special examination for calculus should be made without further delay. The severity of an attack of cystitis depends upon the kind and number of the septic organisms that get in and upon the conditions which favour their growth. Persistence in the face of treatment thoroughly carried out points to some lasting cause which is much more often a calculus than is usually imagined.

Now in many of these cases the prostate is so large, partly from over-growth and partly from long-continued congestion. that the ordinary methods of examination are nseless. A sound, if it can be introduced and rotated in the bladder, cannot be made to explore the post-prostatic pouch or any sacculi that have been formed, without an amount of manipulation that is often most injurious. A cystoscope freqnently cannot be introduced at all, and owing to the length of the prostatic urethra the finger in the rectum cannot lend the least assistance. Hence it is that under these circumstances even large calculi. may be overlooked. But with the Roentgen rays there is no difficulty. Witbout putting the patient under an aræsthetic, without passing. anything up the urethra, without causing pain or even inconvenience, without the least risk of hæmaturia, or septic cystitis, or shock, an examination with the Roentgen rays will prove within the course of a few minutes whether a calculus is present or not, no matter what may be the size or shape of the prostate or how distorted the bladder. Not only can the presence of a calculus be shown, but very valuable information can be obtained as to the size, number, locality, and sometimes even composition. The shadow of the calculus is projected on to the plate with that of the coccyx. (The patient must lie upon his back, as the prone position is only suitable for moveable calculi.) Making allowance for the fact that the coccy $x$ is somewhat nearer to the plate a fairly approximate idea can be obtained as to the size of two of the diameters of the calculus. No direct information, of course, can be obtained as to that of the third. The stone may be discshaped and not thicker than a penny-not an unusual shape in cases of this kind-or it may be spberical. In either case the area of the shadow would be the same. If. however, the shadow on the negative is distinctly lighter than that of the coccyx, in spite of the latter being nearer the plate, it can only mean either that the stone is of considerable thickness, or that it is composed of oxalate of lime, or both. The actual size, however, and the hardness of the calculus are not so material under these conditions as is its position. The material point is that a calculus is present, either behind the prostate or in a sacculus, that it cannot be reached by a sound, and that therefore it is no use trying 
to crush it by means of a lithotrite introduced through the urethra.

There is no need for any exceptional apparatus. It is usually recommended that the tube should be one of low vacuum, as the object is to obtain differentiation rather than penetration. In order to ensure shortness of exposure under these conditions the wattage of the secondary circuit must be high and the amount of the discharge sufficiently large. For this reason a coil giving a 10-inch or 12 inch spark answers better than a static machine. But I have known excellent results to be obtained, even in the case of the kidney, by very short exposure with a decidedly hard tube-and where the patient is very stont the tube must be hard. What is important, is not to obscure the differentiation obtained in the first few minutes' exposure by allowing too much penetration subsequently. The bowels must be cleared out thoroughly. All clothing containing foreign bodies likely to cast a shadow must be removed from the area to be examined. As a rule the patient should be placed in the recumbent position, with the plate, supported by a stout board beneath him, and an aluminium screen between the body and the tube. If it is wished to take a skiagram of the whole - minary tract at once the plate must be large enough to reach from the last dorsal vertebra to the lower part of the pelvis, but it is often better, when there is any doubt, to take two exposures, one of the kidneys and the upper part of the ureter, and the other of the lower part and the bladder.

One of the chief difficulties is the patient's breathing. The kidneys move up and down during even tranquil respiration to a much greater extent than is usually believed. They are not by any means immoveable organs, as anyone who has ever exposed a kidney during life must know. The patient cannot hold his breath for a sufficient length of time. The plan recommended by Mr. Mackenzie Davidson of making him hold bis breath with the thorax fixed in a certain predetermined position, for short periods, at frequent intervals, and only allowing the exposure to take place at those periods, answers fairly well but requires a very careful patient. A more satiafactory plan is either to direct the patient to take very shallow breaths, or, better still, to put a firm bandage around the abdomen. This fixes it in a position of expiration and has the additional advantage of slightly raising up the opaque mass of the liver. The respiratory movement is less when the patient is sitting upright, but this advantage is more than compensated for by the way in which the abdominal viscera descend and conceal the kidneys. In the case of a very prominent abdomen the prone position, with the plate beneath has been recommended instead of the supine position, with the idea that the abdomen would be flattened out to the sides and the kidneys brought nearer to the plate. I hive had no experience of this, or of distending the stomach with carbonic acid gas-a plan which has been suggested as possibly of service in the case of the left kidney, under the impression that the more opaque viscera would be to some extent lilted from off it in front. Distension of the bladder with air in the case of a fixed vesical calculus is certainly of use, and provided the air is sterilised first, and due regard is paid to the sensations of the patient, it may be practised witb nc more danger or unpleasantness than that which attends the process of washing out the bladder.

The negative must be allowed to dry before any conclusion is drawn; and, if there is any doubtful spot, should be intensified with corrosive sublimate. Unless everything is certain a second examination should be made after a few days' interval, and if there is any doubt then a separate exposure shonld be taken of the area in question, a leaden plate with a circular opening exactly opposite the anode being interposed between the tube and the patient, so as to cut off as far as possible all extraneous rays and obtain a bet'er defined shadow. I prefer plates in all cases to flexible films, as the latter are very liable to stretch when handled and give misleading results; but in such a case as that which I mentioned above in which there was an extreme lumbo-dorsal curvature they may be the more suitable in spite of this disadvantage.

Wimpole-street, W.

Bristol Medical Charitias. - The employés of Messrs. W. D. and H. O. Wills of Bedminster, Ashton Gate, and Redcliff-street, have during the past 12 months voluntarily collected the sum of $£ 38918 s$. 11d., which has been distributed amongst the Bristol hospitals and medical charities.

\section{UROTROPINE AS A URINARY ANTI- SEPTIC.}

Bx P. J. OAMMIDGE, M.R.O.S. FNG., L.R.C.P. LoND., ASSISTANT DHMONSTRATOR OF PATHOLOGY, YORKSHIRE COLLEGE, LEEDS ; LATE TREASURER'S RESEARCH STUDENT IN PATHOLOGY, ST. BARTHOLOMEW'S HOSPITAI, E.O.

EARLY in the year $1899 \mathrm{my}$ attention was drawn to the effect produced by urotropine on the urine of a patient under the care of Dr. S. J. Gee in St. Bartholomew's Hospital. In the course of an attack of enteric fever he had developed cystitis, and his urine, which was markedly turbid from the presence of numerous typhoid bacilli and pus, had become quite sterile and clear after some six or seven doses of the drug. Subsequent observation showed that although many cases of cystitis arising from causes other than the typhoid bacillus were also markedly benefited by treatment with urotropine it was not invariably so. This led me to investigate the action of the drug on various micro-organisms and to attempt to determine the form in which it was excreted and the manner of its action in the urine.

Although urotropine or hexamethylene tetramine $\left(\mathrm{C}_{6} \mathrm{H}_{12} \mathrm{~N}_{4}\right)$ bas long been known to chemists as a white crystalline body produced by the action of ammonia on formaldebyde it had not been employed therapeutically until Professor Nicolaier of Göttingen introduced it in 1894 as a diuretic and solvent of uric acid. He further claimed that it would prevent the development of bacteria in the urine. ${ }^{1}$ On attacking the subject experimentally I first endeavoured to discover what effect urotropine had on the urive of a normal individual. For this purpose a healthy adult male was selected and the daily output of urine collected and measured for three weeks. Each day it was quantitatively examined for urea, uric acid, chlorides, phosphates, and sulphates. The specific gravity, reaction, and number of acts of micturition were also noted. The results obtained in the first and third weeks were only used as a standard with which to compare those of the second week, in which 10 grains of urotropine dissolved in an ounce of water were taken three times a day. During the whole course of the experiment the conditions as to food and exercise were kept as nearly as possible constant. It was found that the drug had not any diuretic action nor was any appreciable change in the excretion of the chemical constituents of the urine observed. Urotropine was found in the urine 10 minutes after the first dose was taken and it still continued to be excreted in small quantities 26 hours after the administration had been discontinued. One curious effect produced by the drug was a sensation of formication, which appeared on the fourth day and was most intense at night and in parts pressed on by clothing, \&c. It became more intense each day and on the sixth day a diffuse red rash, somewhat like tbat of measles, appeared. Both rash and irritation quickly subsided after the urotropine was stopped. Usuallv urotropine is well borne, although Nicolaier speaks of 90 grains a day causing blood and epithelial cells to occur in the urine and a burning sensation to be complained of in the bladder. The urine passed during the first and third weeks on standing was found to quickly decompose, but that of the second week, which contained urotropine, remained clear and free from smell for more than four times as long.

All investigators are agreed that much of the urotropine taken by the mouth is passed unchanged, but there is considerable divergence of opinion as to whether the antiseptic properties of the urine are due to the drug itself or to some decomposition product arising from it. It is natural to suppose that if the latter is the case it is the formaldehyde which is set free to exert its well known bactericidal powers. Löbisch, Casper, and A. Citron have stated that 1 ormaldehyde can be obtained from the urine, at any rate in most cases, but the last-named suggests that the active body is not free formaldehyde but a soda compound of it. ${ }^{2}$ Free formaldehyde added to urine precipitates the urea and has been suggested as a means of estimating it. Furtber, the

I Nicolaier: Centralblatt für die Medicinischen Wissenschaften, 1894 and Deutrche Medicinische Wochenschrift, 1895 2 Löbisch : Wiener Klinische Wochenscbrift, 1897, No. 12. Casper:
Deutsche Medicinische Wochenschrift, 1897, No. 45. Citron : Monatsberichte iber die Gesammtleistungen auf dem Gebiete der Krankheiten der Harn- und Sexual-apparate, Band ii., No. 2, 1898; and Teiten der Harn- und Sexu 